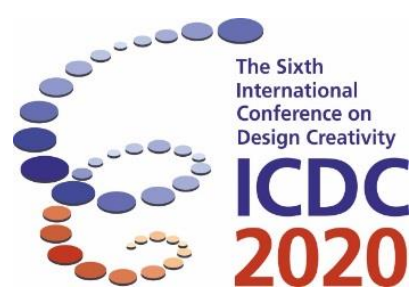

\title{
Sensemaking in the design space: in-betweenness and identity construction of design managers
}

\author{
Tarja Pääkkönen, Melanie Sarantou and Satu Miettinen
}

Faculty of Art and Design, University of Lapland, Rovaniemi, Finland

\begin{abstract}
Identities and notions of the in-betweenness of designers in management positions in Silicon Valley might be shaped by one another given changing sensemaking contexts. As organising becomes less bounded with shorter job tenures designers have been constructing their identities in interactions with diverse stakeholders. Tools, skills and values together with previous experiences continuously shape design manager identities. This research explored design manager in-betweenness by linking it with identity construction, critical sensemaking and social constructionism. While hybrid design managers produce profits and innovations by utilising user data, they also might steer their organisations towards more inclusive values and global responsibility. Internal struggles may follow while there is a need for open interdisciplinary reflection. A broader global understanding of the design space is suggested. Implications for education extend beyond the design field. Deeper reflection on ethics and production consequences across occupational silos enhances critical thinking, enabling collective identity cultivation in organisational sensemaking.
\end{abstract}

Keywords: identity construction, in-betweenness, design space, strategy, sensemaking,

\section{Introduction}

This article reflects on how the in-betweenness of design managers in industrial settings forms a work context for in-house designers and design consultants in managerial positions. As Buchanan (2015) noted, the fourth stage of design broadens the design space to systems, environments and organisations, allowing designers to take more strategic roles. The role of designers in producing innovations has become one of the prominent features of the profession (cf. Hernández, Cooper, Tether \& Murphy, 2018). Meanwhile, shifting positions in boundaryless organisations lead to people continuously constructing their identities (Weick, 2011). For Ricoeur (1992), a person's or community's identity can be defined as their 'identification with values, norms, ideas [and] models' (p. 121). Identity polarities result from notions of 'me', 'us' or 'others', which also introduce the ethical importance of the 'other over the self than the self' (Ricoeur, 1992, p. 168). It is important to understand how design managers make sense of such polarities as designers and as managers and the possible tensions between managerial, organizational, and design-related views.

Professional identity can be understood as interpretations of experiences, beliefs, values and personal qualities relevant to the professional space (Tracey \& Hutchinson, 2018). However, professional identity and its development have not been adequately explored in design literature (Tracey \& Hutchinson, 2018). Identities are plural, layered, dynamic and in flux (Lawler, 2008). Designers' in-betweenness might lead to tensions as identities shape internally and between people (p. 7). In-betweenness can relate 
to hierarchy, being between teams and top management (Gjerve \& Alvesson, 2020, 129) or discrepancies between professional, organizational and personal values. Ahluwalia (2010) refers to experiences of in-betweenness as 'occupying that in-between space - part of their own alterity' (p. 4). Organizational micro-situations, such as strategy workshops, are social sensemaking spaces where designers interact with diverse individuals across silos and industries. Several stakeholder interests become enmeshed in the design space during collective sensemaking (cf. Weick, 2011). Action and reflection merge while values and cues important for individual and collective identities are negotiated (Lawler, 2008). Professionals constructing their personal identities in fractured careers, such as those noted by Delbeckq and Weiss (as cited in Weick, 2011) in the self-defining systems of Silicon Valley start-ups, derive continuity from self-descriptions related to core beliefs, values, tools and skills that are not organisation-specific.

The design community has paid attention to responsibility and ethics for some time, as indicated in 1972 when Cross announced that 'professional designers in every field have failed in their assumed responsibility to predict and to design-out the adverse effects of their projects. These harmful side effects can no longer be tolerated' (p. 11).

Sanders and Stappers (2008) also pointed out that designing has focused more on exploring presumably positive business opportunities than on identifying or improving adverse consequences. Buchanan (2015) repeated the importance of integrating everyone affected by a company's operations. Recently, Bødker and Kyng (2018) problematised the focus on products and technology based on user preference instead of creating solutions that profoundly change activities or goals. For them, the core idea in participatory design is threatened by commercial platforms, big data and large-scale infrastructure. Despite good intentions, harmful consequences abound (Alvesson \& Willmott, 2012) and design management research has leaned on positivist approaches (Johansson \& Woodilla, 2017).

This article suggests that the industrial design space forms the core of in-betweenness for design manager identities positioned between managerial goals and stakeholder needs and interests. Inbetweenness may enable the observation of paradoxical truths where 'differences are honoured while being explored for meaning. There is a genuine willingness to understand rather than a need to be "right" about polarized issues.' (Ventres, 2016, p. 345).

Design manager in-betweenness and identity construction co-evolve during sensemaking in the design space where designers orchestrate organisational strategic issues, users and society interests. Weick's sensemaking frame (1995) is mainly utilised to explore the property of personal identity construction from a critical sensemaking perspective (Helms-Mills, Thurlow \& Mills, 2010).

This article asks:

RQ1. How do design managers in the industrial contexts of Silicon Valley construct their professional identities?

RQ2. What kinds of in-betweens or identity struggles are faced by design managers?

As design manager identities established during earlier education evolve over the course of professional careers in industrial settings, interpreting and refining beliefs about the self, the profession, and the integration of both is needed (Tracey \& Hutchinson, 2018). Identity formation occurs in the movement from intrasubjective to intersubjective, as the self evolves from a singular entity to be part of a collective (Ricoeur, 1992; Weick, 1995). Powerful individuals are more likely to influence the process through which individual identities affect collective identities (Ashforth, Rogers, \& Corley, 2011).

Social realities are constructed by people and affected by their environment and past experiences. The process of socialisation mediates internalisation within the individual consciousness of objectified social structures. Self-evident truths are formed through this sedimented knowledge (Berger \& Luckmann, 1966), creating reality conceptions for individuals on which identities can be built and rebuilt.

\section{Methodology and Philosophy}

Silicon Valley is an agglomeration of design companies working with businesses viewed as unique, given that design is adopted into business reinvention and strategies, particularly in the US (Cooper, Junginger, \& Lockwood, 2009). This article reflects on one cycle of longitudinal interdisciplinary research analysis to understand how design managers among Silicon Valley's design-driven organisations make sense of their professions. Theoretical triangulation was used (Denzin, 1978, as 
cited in Berg, 2001) to obtain multiple perspectives on in-betweenness. Data triangulation over time, specifically from 2013 to 2016, increased data richness. Additionally, the participants represented many organisational forms, fields and managerial positions (Table 1). Investigator triangulation enriched the analysis perspectives on the data as the authors work in design and business education.

Designer identity construction was linked with social constructionism (Berger \& Luckmann, 1966), sensemaking (Weick, 1995) and critical sensemaking (Helms-Mills et al., 2010). Therefore, four themes (core beliefs, values, tools and skills) were chosen as potential identity shapers for the qualitative analysis of interviews (Table 1). These themes were used deductively by searching the recorded and transcribed text for design managers' spontaneous reflections on issues important to their professional selves or in-betweenness. Inductive reasoning enriched the interpretation, enabling other themes to emerge (Berg, 2001). By applying sensemaking when interpreting the findings, an understanding of the situated lives of design managers in terms of their identity construction was obtained as opposed to a determination of truth, as facts (Alvesson \& Sköldberg, 2018).

Table 1: Industry and participant profiles for interviews in Silicon Valley

\begin{tabular}{|c|c|c|c|}
\hline $\begin{array}{c}\text { Silicon Valley } \\
\text { organization field }\end{array}$ & Codes: years & Participants & $\begin{array}{c}\text { Duration of } \\
\text { interviews in minutes }\end{array}$ \\
\hline $\begin{array}{c}\text { Design } \\
\text { consultancies and } \\
\text { start-ups }\end{array}$ & C1-C2: 2013,2016 & $\begin{array}{c}\text { Design Manager, Head of } \\
\text { Operations, Lead Designer, } \\
\text { Service Design Lead, Chief } \\
\text { Design Officer }\end{array}$ & C1-C2:33min, 49min \\
S1-S2: 2013,2016 & $\begin{array}{c}\text { S1-42min, 46min } \\
\text { Multinational IT } \\
\text { corporations }\end{array}$ & $\begin{array}{c}\text { Senior Design Managers, } \\
\text { CEO, Senior Design } \\
\text { Researchers, Innovation Lead, } \\
\text { Design Strategist, Principal } \\
\text { XD Researcher, Strategic } \\
\text { Project Director, Design Lead, } \\
\text { Head of UX Design }\end{array}$ & $\begin{array}{c}\text { IT1-IT7: } \\
18 \mathrm{~min}, 46 \mathrm{~min}, \\
\text { 1hnin,1h26min, 28min, } \\
39 \mathrm{~min}, 47 \mathrm{~min},\end{array}$ \\
\hline $\begin{array}{c}\text { Manufacturing } \\
\text { industry }\end{array}$ & $\mathrm{M}, \mathrm{U}$ (=UX workshop): & $\begin{array}{c}\text { Innovation Manager; Head of } \\
\text { UX Design (user experience } \\
\text { design) }\end{array}$ & $57 \mathrm{~min}, 1 \mathrm{~h} 41 \mathrm{~min}$ \\
\hline Education & E: university 2015 & Design Lead & $38 \mathrm{~min}$ \\
\hline
\end{tabular}

The interviews were collected during benchmarking visits by the University of Lapland Design Research Group. Participants were recruited through snowball sampling (Saunders \& Townsend, 2018) among existing networks of Silicon Valley-based design-driven organisations. Initial contacts enabled the contacting of further participants who each had 10 to 20 years of experience in managerial roles at time of interview. Altogether, 16 interviews including one workshop formed the data corpus for analysis. The in-depth interviews (Johnson, 2002) yielded rich anonymised data. A wide range of design disciplines linked to service, interaction, industrial, graphic, HCI, UX and experience design were covered. This article refers to participants alternatively as 'design managers' or, in short, 'designers'.

\section{Interpreting design manager in-betweenness}

While previous research on sensemaking, such as that by Maitlis and Sonenshein (2010), concentrated on top management or strategic change, Rouleau and Balogun (2011) discovered the mediating role of middle managers in influencing activities across multiple stakeholders: upwards, downwards and horizontally. Knights and Morgan (1991) further suggested that strategic discourse provides professionals with a subjective identity that is supported through participation in its reproduction. Strategy as given becomes a social reality providing legitimation. However, designing, sensemaking and strategising can be viewed as a broader phenomenon in which the strategic direction of organizations is (re)negotiated (Päk̈kkönen, Miettinen, \& Sarantou, 2019). As a result, designers can co-construct activities and conditions with other professionals, that, in turn, continuously shape their identities and guide strategic direction. 
While identities are likely to be more fluid than stable over time, context matters as well (Helms-Mills et al., 2010). Identities are shaped continuously as people seek more coherence in their fragmented experiences (Weick, 2011). Silicon Valley start-ups exemplify self-organising systems where broad boundaryless organising leads to more intense micro-level interactions due to actors seeking order when confronted with uncertainty (Weick, 2011). Casoni (2010) pointed to socioeconomic ecosystems where actor proximity, such as the networked design community (Katz, 2015), is important. This context can be understood as a design space where social interactions shape the identities of participants mediating personal meaningfulness and their acceptance of what constitutes the merging of identities into collective and more compromised justifications. Norms, rules and expectations advance some values over others while strategy as truth legitimates action but can also lead to individual tensions (Lawler, 2008).

Viewing designers as innovators (Hernández et al., 2018) may guide professional designer identities as a normative conception of action, defining appropriate or acceptable behaviour. It can also provide an opportunity to improve the lives of human beings and transform organizations and society (Irwin, Kossoff, \& Tonkinwise, 2015). However, Elsbach and Stigliani (2018) suggested that research on design thinking has largely overlooked design as a key component of organisational culture due to focusing on business problems. They find design thinking tools (user-centric focus, collaboration, risk taking, and learning tools) and organizational cultures mutually supportive. The coupling between design tools, which include rapid prototyping, user observation, visualisation of ideas, or brainstorming (Elsbach \& Stigliani, 2018; Liedtka \& Ogilvie, 2011), and organisational cultures suggests they are important for collective identity construction. Events such as codesign workshops exemplify tighter micro-level interactions in looser systems; a familiar way of working that may sustain design manager identities while triggering tensions.

Design tools and methods can be used to support design values as well as intensify awareness and adoption of managerial goals. Such use may lead to adjusting identities towards or away from promoted ideas. Internal struggles may follow when designers encounter ethical issues related to technology, sustainability or responsibility (Chan, 2018), especially if organizations view designers as profitgenerators.

Fayard, Stigliani, and Bechky (2017) found service designers to construct an occupational mandate through specific values at the core of their ethos: holism, empathy, and co-creation. Designers often differ from other professionals by internalizing such values in their education, contrary to traditional business logics.

\section{Fluid Design Manager Identities}

Core beliefs, values, tools and skills (Weick, 2011) were frequently mentioned among Silicon Valley design managers. Their in-betweenness emerged in many layers and forms, including hierarchy, between others and between values.

\subsection{Core Beliefs and Values}

Generally, there was a strong belief in a collective goal; transformation meant adopting design principles and methods across entire organisations. The main means to such an end was exposing stakeholders to design. The beneficial effects of design were shared eagerly with non-designers. With a design culture, better organisations were assumedly developed through enhanced customer and employee experiences. There was a strong belief in what design could do. What prevailed was a sense of a community (Participant IT4a used the word) or a movement rather than a department. It was 'the golden era of design' (Participant S2). However, some designers implied that they were not being understood at times. Mostly, breaking silos and teaching design were the triggers fuelling these designers. By breaking routines for others, sensemaking was triggered. Innovation was the dream. Seeking business opportunities drove organisations and design managers' awareness of the need to show results quickly. Transformation and innovation, however, seemed to become entangled into a somewhat vague dream. The design managers depicted their positions as firmly rooted. Supported by enlightened (top) management, there remained only limited questioning about their legitimation. Having strong ties with top management further strengthened their positions when circulating in Silicon Valley, sharing 
knowledge and changing jobs actively (cf. Katz, 2015). Personal development, as Weick (2011) suggested, seemed to be more important than advancing in hierarchy or titles:

You need to be humble but hungry; it is more important than titles. (Participant IT4b, 2016)

The designers identified themselves strongly with the strategies they explored or implemented:

Design is a strategic tool. (Participant C2, 2016)

Professional designers can form a strategic thinking division of a company. (Participants IT7 and U, 2016)

Understanding users brings about opportunities for a company. (Participant M, 2016)

Among these design managers, exposing others to design methods was a passion. Constraints, if any, only fuelled innovation. By identifying themselves with their goals, such as competitive advantage and innovation, the design managers adopted managerial goals and values, disseminating them by including diverse stakeholders. However, the designers referred delicately to tensions, suggesting some inbetweenness at times even though tensions were mostly viewed as positive cues for further innovation. The designers aimed at seamless services and systems with some focusing on breaking power structures and many on representing end users next to the paying business stakeholders. Their in-betweenness and tolerance were exemplified when translating issues from one group to another:

...the kind of user research and deep user insights that guide the whole organisation. (Participant IT4b, 2016)

...involve stakeholders that normally would not be involved... (Participant M, 2016)

This innovation catalyst thing...they're not just designers. We have people who are in HR, people who are in IT, people who are in legal, you know, like, all over the company. (Participant IT4a, 2013)

The challenge ... maybe bringing everybody on the same table... so you try kind of further discussions forward, in a way. (Participant M, 2016)

... maybe it's hard to find a perfect match between myself and company...but at least there is overlap...(Participant IT7, 2016)

These design managers guided and supported management struggling with uncertainty. Empathy was equally enacted upwards, across teams, and to other stakeholders.

\subsection{Design Tools and Skills}

The designers identified strongly with their tools and methods. In alignment with the literature review by Hernandez et al. (2018), much attention was paid to a variety of tools in diverse settings. For example, probing continuously distinct from prototyping supported organisations in maintaining trend awareness. Design consultants distilled strategies for start-ups. As translators of issues at hand, the language of managers, designers or engineers was spoken. Visualisations were used for clarifying strategies and ideas created for branding, storytelling or digital touchpoints.

Digitalisation, the Internet of Things, VR, machine learning and artificial intelligence were considered design materials with infinite affordances. Self-reporting tools or ethnographies were utilised to understand people's lives. Designers moved from form and function towards competitiveness by utilising user data. Data analytics were used to customise brands while applications were developed for 
customers identified on social media. As mediators between occupations and industries as well as by being facilitators and translators of user data, designers interacted with marketers, strategists, coders and engineers who required user experience awareness. Multiple degrees and career changes were considered positive designer features. A hybrid designer, among other things, needed to understand cultures, reach into other fields, possess communication skills, cope with ambiguity and be flexible. However, a participant (S2) stated that creativity expression was antithetical to staying in business. Another participant (IT2a) noticed that some designers were not comfortable with group facilitation. Some sought non-commercial networks to talk with, relying on less formal contacts with other designers.

\section{Discussion}

Design manager in-betweenness, their stretching into multiple worldviews, might lead to identity pressures (Chan, 2018) due to value and belief discrepancies in their work contexts as cross-disciplinary hybrid professionals. In-betweenness appears on many levels: cross-disciplinary interactions cause adoption of the varying languages of management, users and engineering as well as translating between stakeholders. The design manager is expected to implement strategies while creating innovative ones. Just like their organisations, designers cope with uncertainty. This skill (Tracey \& Hutchinson, 2016) might strengthen their identities. As no future is definitive, expressing in-betweenness via tolerance (Ventres, 2016) seems natural for a designer.

As to hierarchy and being in the middle (Gjerde \& Alvesson, 2020) the design managers were empowered by senior management. There was no sign of interest in power play. However, the designers worked across silos with the intent of bringing people together.

Personal or corporate ethics were largely not discussed. Chan (2018) suggested that design can be selfcritical, but is threatened by self-negation. Internal struggles caused by professional situations and norms (Chan, 2018) may not surface easily. Considering decades of strategy discourse (Knights \& Morgan, 1991), professionals understandably absorb beliefs and norms prevailing in business thinking. The identity of a good employee may be favoured through language or rules encouraging characteristics and behaviours of a certain type (Helms-Mills et al., 2010), such as an innovative hybrid designer or a need to learn the language of business.

Designers face unarticulated identity pressures. Sometimes, users or employees are given more voice with the support of empathy, a key attitude among designers (Michlewski, 2008). Yet, most activities focused on fast success instead of openly considering negative consequences. Strategic beliefs were easily reproduced (Knights \& Morgan, 1991); an intensive design workshop might convert traditional ideas into modern forms. By focusing on key strategic elements, organisations may ignore other environmental cues (Helms-Mills et al., 2010). It is difficult to raise problematic issues taking place outside the walls of an innovation factory that has paid little attention to harmful production consequences (Alvesson \& Willmott, 2012; Sanders \& Stappers, 2008).

Designers, managers and educators across professional fields are encouraged to view the world as a single design space affected by local decisions and strategies beyond occupational borders, which requires ethical reflection (Chan, 2018). While not an easy task, a broader view might support designer identity construction and align with some values originally called for in the design community by Cross (1972) and others. For example, design managers might trigger reflection by visualising and concretising production consequences. Considering the in-betweenness of design managers, they may be strong players when steering organisations or may be steered by them, making it crucial for individual designers to reflect on themselves and their profession (Tracey \& Hutchinson, 2016) and encourage others to do so. However, a lack of emotional reflection (Tracey \& Hutchinson, 2016) in professional contexts can also be a sign of self-protection. Power ultimately may produce subjectivity (Knights \& Morgan, 1991), defining personal individual identity in terms of desirable ways to display rational professionalism. Rather than articulating issues, designers may instead act and show empathy to include those without voices.

Limitations admittedly apply to the interview situation and limited time. The need to represent the company placed interviewees in another in-between position. The researchers' own background has undoubtedly affected the results. Cultural differences may have led to misinterpretations. The research 
does not seek to generalize. Further research on design managers' identity struggles is important considering the influence design has on creating images of possible futures.

Design manager in-betweenness both limits and enables deeper reflection that might cultivate individual and collective identities leading to organisational cultural transformation suggested by Buchanan (2015). Ethics can prompt new avenues for design understanding, which may catalyse new research or design innovations (Chan, 2018).

\section{Conclusion}

This article reflected on design managers' entangled in-betweenness and identity construction. Tools and skills formed a substantial part of designer manager reflection and implied their importance for individual and collective identities. Teaching design skills and exposing non-designers to the experience were believed to have a positive transforming effect on those involved. The design managers mostly had support from top management, which further supported their identities as co-strategists, translators or facilitators. Design manager in-betweenness balanced a hybrid professional identity, designing for profit and innovations, and following a design ethos of empathy, holism and co-designing. Designing for profit and pleasure through utilisation of user data is common. Due to their in-betweenness, the design managers were subjected to identity pressures, but this research encourages them to invite others into collective sensemaking towards responsibility and sustainability beyond profits.

\section{Acknowledgements:}

We express our gratitude to our peer reviewers. Business Finland funded the projects MediPro (2012-2013), HumanSee (2015-2016) and N4S (2014-2017) enabling data collection.

\section{References}

Ahluwalia, P. (2010). Out of Africa: Post-structuralism's colonial roots. Routledge. London, UK: Routledge Alvesson, M., \& Willmott, H.C. (2012). Making sense of management: A critical introduction (2nd ed.). London, UK: Sage Publications.

Alvesson, M., \& Sköldberg, K. (2018). Reflexive methodology. New vistas for qualitative research (3rd ed.). London, UK: Sage Publications Ltd.

Ashforth, B. E., Rogers, K. M., \& Corley, K. G. (2011). Identity in organizations: Exploring cross-level dynamics. Organization Science, 22(5), 1144-1156.

Balogun, J. (2003). From blaming the middle to harnessing its potential: Creating change intermediaries. British Journal of Management, 14(1), 69-83. doi:10.1111/1467-8551.00266

Berg, B.L. (2001). Qualitative research methods for the social sciences (4th ed.). Boston, MA: Allyn \& Bacon.

Berger, P. L. \& Luckmann, T. (1966). The social construction of reality. New York, NY: Penguin Books.

Buchanan, R. (2015). Worlds in the making: Design, management, and the reform of organizational culture. She Ji: The Journal of Design, Economics, and Innovation, 1(1), 5-21.

Bødker, S., \& Kyng, M. (2018). Participatory design that matters-facing the big issues. ACM Transactions on Computer-Human Interaction, 25(1), 4:0-4:31. doi:10.1145/3152421

Casoni, G. (2010). Design and creativity in open innovation processes: The case of Italian industrial districts. Strategic Design Research Journal, 3(2), 33-40. doi:10.4013/sdrj.2010.32.01

Chan, J. K. H. (2018). Design ethics: Reflecting on the ethical dimensions of technology, sustainability, and responsibility in the Anthropocene. Design Studies, 54, 184-200. https://doi.org/10.1016/j.destud.2017.09.005

Cross, N. (Ed.). (1972). Design participation: Proceedings of the Design Research Society's conference 1971. London, UK: Academy Editions.

Cooper, R., Junginger, S. \& Lockwood, T. (2009). Design thinking and design management: A research and practice perspective. Design Management Review, 20(2), 46-55.

Elsbach, K. D., \& Stigliani, I. (2018). Design thinking and organizational culture: A review and framework for future research. Journal of Management, 44(6), 2274-2306. doi:10.1177/0149206317744252

Fayard, A-L., Stigliani, I., \& Bechky, B. A. (2017). How nascent occupations construct a mandate: The case of service designers' ethos. Administrative Science Quarterly, 62(2), 270-303.

Gjerde, S., \& Alvesson, M. (2020). Sandwiched: Exploring role and identity of middle managers in the genuine middle. Human Relations, 73(1), 124-151. doi:10.1177/0018726718823243 
Helms-Mills, J., Thurlow, \& Mills. A. J. (2010). Making sense of sensemaking: the critical sensemaking approach, Qualitative Research in Organizations and Management: An International Journal, 5(2), 182-195.

Hernández, R. J., Cooper, R., Tether, B., \& Murphy, E. (2018). Design, the language of innovation: A review of the design studies literature. She Ji: The Journal of Design, Economics, and Innovation, 4(3), 249-274.

Irwin, T., Kossoff, G., \& Tonkinwise, C. (2015). Transition Design Provocation. Design Philosophy Papers, 13(1), 3-11.

Johansson, U., \& Woodilla, J. (2017). A critical Scandinavian perspective on the paradigm dominating design management. In R. Cooper, S. Junginger, T. Lockwood, R. Buchanan, R. Boland, \& K-W. Chung (Eds.), The handbook of design management (pp. 461-479). London: Bloomsbury Academic.

Johnson, J. M. (2002). In-depth interviewing. In J. F. Gubrium \& J. A. Holstein (Eds.), Handbook of Interview Research: Context and Method (pp. 103-119). Thousand Oaks, CA: Sage.

Katz, B. (2015). Make it new: The history of Silicon Valley design. London, UK: The MIT Press.

Liedtka, J., \& Ogilvie, T. 2011. Designing for growth: A design thinking toolkit for managers. New York: Columbia University Press.

Knights, D., \& Morgan, G. (1991). Corporate strategy, organizations, and subjectivity: A critique. Organization Studies, 12(2), 251-273. doi:10.1177/017084069101200205

Lawler, S. (2008). Identity: Sociological perspectives (1st ed.). Cambridge, UK: Polity Press.

Maitlis, S., \& Sonenshein, S. (2010). Sensemaking in crisis and change: Inspiration and insights from Weick (1988). Journal of Management Studies, 47, 555-556.

Michlewski, K. (2008). Uncovering design attitude: Inside the culture of designers. Organization Studies, 29(3), 373-392. doi.org/10.1177/0170840607088019

Pääkkönen, T., Miettinen, S., \& Sarantou, M. (2019). A model of positive strategic sensemaking for meaningfulness. Conference Proceedings of the Academy for Design Innovation Management, 2(1), 710-721.

Rouleau, L. \& Balogun, J. (2011). Middle managers, strategic sensemaking, and discursive competence. The Journal of Management Studies, 48(5), 953. doi:10.1111/j.1467-6486.2010.00941.x

Sanders, E. B-N. \& Stappers, P. J. (2008). Co-creation and the new landscapes of design, Co-Design, 4(1), 5-18. Saunders, N. K., \& Townsend, K. (2018). Choosing participants. In C. Cassell, A. L. Cunliffe, \& G. Grandy (Eds.). The Sage handbook of qualitative business and management research methods (pp. 480-494). London, UK: Sage Publications.

Ricoeur, P. (1992). Oneself as another. (1992). Trans. Kathleen Blamey. Chicago, IL: University of Chicago Press. Tracey, M. W., \& Hutchinson, A. (2016). Uncertainty, reflection, and designer identity development, Design Studies, 42, 86-109. doi:10.1016/j.destud.2015.10.004.

Tracey, M. W., \& Hutchinson, A. (2018). Reflection and professional identity development in design education. International Journal of Technology \& Design Education, 28(1), 263-285.

Ventres, W. B. (2016). Building Power Between Polarities: On the Space-in-Between. Qualitative Health Research, 26(3), 345-350. doi:10.1177/1049732315609573

Weick, K. E. (1995). Sensemaking in organizations. London, UK: Sage Publications.

Weick, K. E. (2011). Making sense of the organization. Oxford, UK: Blackwell Publishing. 